\title{
Dialéctica de colapso del mundo y la existencia
}

\author{
M.Ph. Hermann Güendel* \\ Recibido: noviembre 2010 - Aceptado: febrero 2011
}

\section{RESUMEN}

Exploro en este ensayo los alcances distorsionadores que el colapso del sistema mundo capitalista neoliberal posee sobre la cotidianidad; proponiendo que la solución a sus efectos se gesta en la dinámica de cogestión de nuevas formas identitarias de ser, pensar y actuar frente a la exclusión, que la diversidad humana realiza desde el espacio vivencia de resistencia al que llamamos colectivos. Se deja de lado la imprescindible relación entre hombre y medio, por lo cual este se va dañando a sí mismo aun cuando no lo crea. La violación indiscriminada de una, es el efecto bumerán del otro, el cual, tarde o temprano ha de recibir los efectos de sus actos. Es por ello que esa relación de "beligerancia" debe ser objeto hoy de discusión y el ser humano debe darse cuenta de que sus actos no pueden permanecer sin repercusión. No es el amo de la naturaleza, sino una parte más de esta. Los movimientos en pro de la naturaleza hoy no son más que la necesidad de un aviso de que las consecuencias se vienen dando a pasos agigantados y los meros avisos ya no son tales, sino realidades palpables.

Palabras clave: Sujeto, resignificación, mundo.

\begin{abstract}
In this essay I explore the distorting scope that the collapse of the neoliberal capitalist world system has on daily life, suggesting that the solution to its effects dwells in the co-management dynamic of new identity forms of being, thinking and acting against exclusion, that human diversity applies from a "living the ressistance" space that we call "collectives". I do not consider the essential relationship between man and environment, by which he is harming himself even when he does not create it. The indiscriminate violation of one, is the boomerang effect of the other, which, sooner or later has to receive the effects of his actions. That is why this relationship of "belligerence" should be discussed today, and man must realize that his actions cannot remain without impact. Man is not the master of nature but a part of it. The pro-nature movements of today are but the need for a warning that the consequences have been evolving rapidly and are no longer mere warnings, but full realities.
\end{abstract}

Key words: Subject, "re-signification”, world.

* $\quad$ Máster en Filosofía por la Universidad de Costa Rica, autor de numerosos artículos en publicaciones universitarias y revistas especializadas en Filosofía, actualmente es subdirector de la Escuela de Filosofía de la Universidad Nacional de Costa Rica 


\section{El colapso de los significados}

Décadas de tensa estabilidad en la realidad histórica llevaron a la conciencia al desprecio de una lúcida advertencia: la naturaleza no resistiría por mucho tiempo más su sometimiento a la pasión humana.

Agotada la vitalidad de la realidad histórica esta no puede detener más la tensión que generó sobre el mundo, este se precipita a su decadencia, desde la cual el ser humano remira a la naturaleza descubriendo que ella ha entrado un proceso de desgaste al que no se le contrapone voluntad humana de contrarrestarlo, revertirlo y resignificarlo. De un modo extraordinariamente lúcido Saxe Fernández escribió en el 2004:

"Ecológicamente, observamos que los procesos destructivos tienden a encadenarse, provocando sinergias devastadoras entre diferentes ecosistemas o componentes de los mismos. Las características de cruciales procesos ecológicos mundiales se van extremando, agudizándose sus características (más serio y más calor, más lluvia y mas sequía, rupturas repentinas de la atmósfera o de las montañas y laderas, una creciente extensión de zonas desoxigenadas en el mar donde sucumbe la vida). No sabemos cuando esas sinergias provocarán un salto, un colapso, un cataclismo, como por ejemplo nuevas y mayores rupturas o desagregaciones desde la atmósfera mundial." (Saxe, 2004:27)

El proyecto de mundo forjado por el capitalismo ha quedado sin asidero posible, la decadencia de un tipo de realidad histórica ha pervertido al espíritu humano. Hoy, como narrativa inhibidora, se extiende una sensibilidad que no reconoce significados y niega la pasión de reasignarlos. Desventurada nuestra conciencia ve a su mundo con una realidad agotada, coloca a la muerte por encima de la existencia, como si ella diera algún significado a la vida, el ser humano se aferra entonces a instantes pasajeros y los excita.

La simple formulación de proyectos de significado vital, algunos tan simples que resultan vulgares, otros tan sublimes que resultan risibles, no son más que expectativas transitorias, la conciencia deambula por la realidad que no le importa, los sueños se fragmentan en ilusiones dispersas, el ser humano se vincula la relaciones constitutivas del mundo, las cuales, abandonadas a su orfandad se deterioran. Hemos renunciado a la pasión por la vida, envilecidos por la perversión de la realidad histórica agotada.

La vida es un acto pasión, no es la muerte la que da significado a la vida, es la vida la que da magnitud a la muerte; se vive en la pasión de gestar significados comprensibles, 
de dar coherencia a nuestra realidad con nuestras posibilidades. De la tensión entre la pasión de la vida y el desprecio por lo que nos carece de significado surge, en nuestro espíritu, la voluntad de materializar nuestra dignidad.

Envilecida por su desventura, nuestra conciencia ve a la realidad por entero bajo la categoría de colapso, un agotamiento integral que se percibe como concluyente simplemente porque en el contexto de una sociedad decadente no le es posible reconocer la posición fundamental del hombre dentro de las relaciones constitutivas del mundo; peor aún, las distorsiona hasta desarticularlas.

Es esta perversión del espíritu la que le da significado a una apocalíptica desesperanzadora; es este colapso de los significados humanos el que desde narrativas escatológicas europeas y prehispánicas sólo logra configurar discursos de desasosiego, tragedia e inevitabilidad.

Más que el fin de los tiempos, el no obviable desgaste de la naturaleza, provocado por la barbarie devoradora capitalista, es una tensión generada por un proyecto de mundo agotado, el cual por efecto de su propia decadencia agota, en el ser humano más simple, la pasión de resignificar, reconstruir, reconfigurar un mundo que debe ser nuevamente habitable.
La sensibilidad tanática y apocalíptica que el capitalismo en decadencia ha generado en el espíritu humano no es más que un impasse en el que la generación de alternativas se ve debilitado por la destrucción, ante los ojos de miles, de los sentidos que le habían dado significados su existencia autorizándolos a disfrutar de un goce de apariencias.

No es el mundo el que colapsa, no es la realidad natural la que se encuentra en un momento inevitablemente incorregible, es más bien el espíritu humano el que, colapsado por su envilecimiento, se niega a sí mismo el derecho de reconstruir su realidad corrigendo desde su posición fundamental los infortunios creado por un proyecto colapsado.

\section{El colapso de la existencia}

El ser humano sobrevive hoy la incertidumbre de su mundo, en una situación de orfandad de significados; envenenado por la decadencia de un sistema mundo asimétrico y sacrificial, ha agota toda esperanza entre escatologías ficcionales e inversiones de la relación entre la vida y la muerte.

El colapso del sistema mundo capitalista distorsiona la posición fundamental del ser humano ante el mundo; el espíritu humano se ve acorralado, acogiéndose, cual insensato, a una sensibilidad 
apocalíptica desde la que no logra configurar más que discursos de desasosiego, tragedia e inevitabilidad. La crisis integral del mundo lleva a que la existencia se vacíe significados. Con gran agudeza en su obra, lo nota E. Trias cuando escribe:

"No existe en el horizonte, nada que pueda atisbarse como superación de la modernidad en crisis. La modernidad es crisis en ausencia misma. En ella entre en crisis el sólido y milenario orden del mundo en lo social, en lo político, en lo ético, en lo estético, en lo psicológico, el odontológico había llegado a ser creencia firme, inquebrantable. Esta crisis, desde luego no se produce de modo unívoco y coordinado, sino a modo de confluencia contagiosa en todo los ámbitos del ser, del decir, del hacer o del compartir". (Trías, 1987:122)

Existir es vivenciar los significados en la cotidianidad, pues es solo en la experiencia donde del sujeto se abre al agrado o al desprecio con lo diario. Hoy, en el colapso del sistema mundo capitalista, nadie puede abrirse a lo uno o a lo otro, menos aún encontrar un breve refugio en entre telones estéticos o eróticos. Es por ello, que nadie puede apegarse a una existencia que carece de vida; el brillo de la vida se desgarra de la existencia, escapándosenos como agua entre los dedos. Pero a diferencia de otros momentos de crisis, donde el ser humano tenía la tendencia acabar con su propia vida, hoy prefiere acabar con la vida de otros, en el primer semestre del 2009, mientras que el índice de suicidios en los Estados Unidos aumentó de $5.7 \%$ a $7.5 \%$, el índice de homicidios aumentó de un $8.9 \%$ a un $15.8 \%$

Más que por peso del colapso en su proyecto de mundo, por el desprecio de los condenados a la incertidumbre, la sociedad capitalista no logrará revertir la situación que ha generado, mucho menos provocará que las conciencias despierten para resignificar el mundo que se desintegra. No superará su crisis integral pues es imposible que se genere dentro de ella una reivindicación integral del ser humano, desde otro lugar que no sea el que lo reduce, a él y la naturaleza, a categorías económicas unidimensionalizadas por la generación de ganancias.

El espíritu humano, envilecido por la decadencia del capitalismo, colapsa porque el régimen de significados que lo llevó a olvidarse de sí como sujeto, centrándolo en el disfraz de una individualidad inexistente, ha desvirtuado su capacidad comunitaria de reconfigurar el mundo.

La persona no vale en su individualidad; la imagen de individuo es tan sólo una ficción pervertida del verdadero valor y significado 
de ser un ser humano, un ser comunitario; la persona es un sujeto significativo de comunidad.

Vivimos dentro de un mundo saturado por decadencias y desgastes, una realidad histórica que colapsa, pues como bestia inaudita devora sus entrañas, la persona humana misma. La necrofilia emergida de su decadencia, convierte a la muerte en un objeto de negocio, colocando la imagen del fin de los tiempos sobre una existencia vacía, agotando la voluntad de resignificar y recobrar vida.

Vivir es un acto apasionado de creación de significados; la intensidad de sus contenidos da placer a la vida, una satisfacción materialmente comprensibles que emerge de la polifonía inagotable del espíritu humano al constituir su realidad histórica, el ser humano es un creador de mundos.

Frente a ello, el fin de los tiempos, la escatología actual, no es más que un pseudo sentido, una sensibilidad incomprensible sí, pero envilecedora y por ello despreciable, aún cuando resulte a unos cuantos muy rentable.

Nada que no instaure en el ser humano la esperanza es digno de él. Nada que no implique la resignificación del mundo puede prevalecer en él, pues sin el compromiso apasionado de la voluntad humana, nada puede subsistir por mucho tiempo.

\section{El colapso en el significado de existir}

El colapso del sistema mundo capitalista provoca que nuestra existencia se desgaste entre objetividades agobiantes; la existencia se vuelve incómoda, se divorcia de la vida, pues es incapaz despertar la pasión suficiente para comprometer al espíritu humano en la creación de nuevos significados. Con gran simpleza lo había expuesto ya Fernández Vázquez:

"El mundo inmediato de la expe-
riencia es contradictorio en la me-
dida en que su misma facticidad
niega su posibilidad... esta apre-
ciación ontológica se da en una
dimensión concreta, histórica, Que
dadas las condiciones del sistema
capitalista, se ve invalidada por una
racionalidad puesta desde afuera.
El razonamiento capitalista instru-
mentaliza la realidad obedeciendo
las necesidades de perpetuación de
una realidad en la que la posibilidad
se inhibe" (Fernández, 1979:29)

Existir es simplemente vivenciar los significados de ser con los que nuestra cotidianidad adquiere coherencia. La cotidianidad es la vivencia de experiencias diversas, dispersadas en lugares y momentos inter-sujetales. Esas múltiples y, a veces, vertiginosas experiencias, sólo se relacionan entre sí por sujeto que las vive. 
Vivir es complejo, es crear los significados de ser con los que organizar la cotidianidad experimentada en experiencia cotidiana de significados. La vida posibilita la existencia, los significados cercan la cotidianidad con fronteras de sentido. Las diversas experiencias se interpretan dentro de marcos valorativos sólidos y seguros, comprensibles por su contenido material: la identidad con la realidad histórica dentro la que se gestan. Por ello, una modificación en ella produce una distorsión en aquel; esto es justamente lo que está sucediendo el momento actual de colapso del sistema mundo capitalista. Los significados que daban coherencia de la existencia dentro de la sociedad capitalista, progresivamente se desarticulan como efecto de su colapso; la existencia se vuelve así una vivencia monótona que no permite la irrupción de momentos de vida, pues la valoración de lo diverso sólo se da a través de la frágil reiteración de espacios acostumbrados y tiempos rutinarios. La existencia se ha vuelto tan gris como el futuro de la sociedad donde transcurre.

La identidad de un sujeto está constituida por sentidos de ser que, vinculados sintéticamente, constituyen una forma de existir reconocible. El sujeto es alguien en tanto configure una identidad reconocible, la identidad de la persona se constituye por relaciones sintéticas heterárquicas. En su momento Cassirer entrevió el problema al escribir:

"El hombre no puede escapar de su propio logro, no le queda más remedio que adoptar las condiciones de su propia vida, ya no vive solamente en un puro universo físico, sino en un universo simbólico. El lenguaje, el mito, el arte y la religión constituyen parte de este universo, forman los diversos hilos que tiene en la red simbólica, la urdimbre complicada de la experiencia humana. Todo progreso en el pensamiento y experiencia asigna y refuerza esta red. El hombre no puede enfrentarse ya con la realidad de un modo inmediato, no puede verla, como si dijéramos, cara a cara. La realidad fisica parece retroceder en la misma proporción que avanza su actividad simbólica. Se ha envuelto en formas lingüisticas, en imágenes artísticas, en símbolos míticos que fueron ritos religiosos, que no puede ver o conocer nada sino a través de la interposición de este medio artificial." (Cassirer, 1982: 47-48)

La estabilidad de esas relaciones sintéticas depende de la solidez material en las condiciones sociales de experiencia intersujetal. Las rupturas y desarticulaciones en esas condiciones de la cotidianidad vacían de contenido los significados, vaciando entonces su identidad, desembocando en una vivencia incomprensible; el sujeto se dispersa entre situaciones, volviéndose tan 
incomprensible para sí, como para otros. La existencia cae en desasosiego y lo lleva al anonimato; la soledad le asalta el alma, la muerte se transforma en la única esperanza urgida de ser abrazada.

Las relaciones sintéticas identitarias se constituyen por exigencias de sociabilidad, por ello la persona ante la ausencia de identidad, se transforma en un ermitaño que vive en ciudad, no conoce siquiera el aspecto de sus vecinos $\mathrm{y}$, en el peor de los casos, se transforma en verdugo de quienes, amándolo, aún lo rodean. El reconocimiento de la humanidad en el otro se torna borroso y esporádico, siendo un estatus de privilegio que se le asigna.

La crisis en las condiciones de cotidianidad hacen irreconocibles los significados identitarios que se vivencian, la existencia se disocia de la posibilidad de visibilizar espacios y tiempos de vida; en el colapso del sistema mundo capitalista la cotidianidad incomprensible destierra del alma humana la pasión por reformarla, el ser humano se criminaliza, judicializando a los otros con más desprecio, represión $\mathrm{y}$ anonimato.

Mientras que la existencia oscila entre el placer y el desprecio, la vida tan sólo gira en torno a la pasión intensa de crear y reorganizar el mundo, nada tan lejano a la vida como lo monótono, gris y desapasionado que nos encierra dentro los límites de la desesperanza, nada tan lejano a la vida como este momento de colapso donde las únicas experiencias posibles son la frustración y el desasosiego. Por ello no debe extrañar que la cotidianidad del colapso nos golpee el rostro con continuos asesinatos y manifestaciones de deseos apocalípticos de muerte, ya que la muerte es la única expectativa a la que se puede aferrar aquel cuya existencia se ha vaciado de vida.

\section{La resignificación como alternativa al colapso}

El mundo es una articulación de realidades comprensibles y significados asignados. Configurado por el esfuerzo humano, orientado colectivamente por un marco categorial de relaciones vivenciales específicas del capitalismo, es un sistema estructurado de interacciones sistémicas, tanto conductuales como valorativas y de interpretación, que configura segregaciones humanas, segmentaciones ontológicas y ficciones conceptuales. Un sistema mundo capitalista cuya firmeza depende de lo "evidente" que resulten sus articulaciones para negar alternativas, pues con un conclusivo "no puede ser de otro modo" la pasión de los argumentos se convierte en voluntad y compromiso. 
La solidez de las articulaciones que constituyen el mundo involucran firmemente una forma específica de voluntad; por ello la conciencia de las asimetrías estructurales del sistema mundo capitalista no genera ni un discurso de alternatividad, ni una práctica alternativa generalizada, sino un conjunto de falsas expectativas vivenciales que constituyen un rango civil de conductas coherentes, egoístas y "normales". Reguera expuso esto, particularmente, del modo siguiente:

"El mundo siempre es un mundo, un mundo cualquiera, pase lo que pase en cada época y en cada caso: una construcción lógica o ideológica cualquiera. ¿Qué más da, para lo que importa? Ninguno es necesario. Lógicamente todos son igual: uno cualquiera. ¿Alguien, por ejemplo, puede ver algún sentido relevante en la historia que no lo ponga él? ¿A alguien puede interesarle un mundo que no sea el suyo? Imposible, si le interesa, ya no es. El valor auténtico está en el sujeto que se siente en el mundo desde una perspectiva justa y eterna." (Reguera, 1994:79-80)

Al perder la capacidad de sostener esas expectativas vivenciales, este sistema mundo en crisis integral dirige al espíritu humano hacia su negación, la voluntad no se compromete con el sostenimiento de sus articulaciones constitutivas pues no hay argumentos que la sustenten, las conductas "normales" se disuelven progresivamente en conductas de abandono, desmotivación, incomprensión, insatisfacción, y violencia hacia otros.

Vaciado el espíritu de esperanza, la existencia de vida, el rango de coherencia conductual civil no se reconfigura, desafortunadamente, en prácticas de alternativización generalizada, aun y cuando sea evidente que, si bien de modo focal, existe alternativización a través de actores, sujetos, colectividades y saberes diversos que no pueden ser silenciados hoy, como lo fueron tan solo unos años atrás.

El mundo se ha convertido en un desierto poblado por anónimos que sólo se perciben como amenazas, siendo entonces objetos que se reflejan entre sí con el más profundo desprecio y horror. Este callejón sin salida, producido por el mismo sistema mundo capitalista evidencia el impacto pervirtiente que posee la reducción capitalista del ser humano a la prisión conceptual de individuo tras siglos de hegemonía. Bajo el peso de esa categorial superestructural se le arrebata a la existencia humana, la posibilidad de dinamizar vivencialmente la cotidianidad del tiempo y el espacio con el placer intenso de la construcción colectiva de nuevas proximidades o relaciones íntimas y filiales.

De los diversos nudos estructurales del sistema mundo capitalista, 
el que genera mayor perversión de la existencia es el de la ficción conceptual de individuo; con él, la construcción colectiva del mundo se resuelve en una configuración vivencial de "existencia cómoda". La valoración de la individualidad por encima de la co-gestión de realidades, lejos de hacer evidente que la confluencia de significados de ser posibilita la confirmación de la vida, enajena las posibilidades de vivir múltiples experiencias diversificadas, el sujeto reducido a individuo se hunde así en la monotonía del tiempo y la reiteración del espacio.

Los efectos estructurales del sistema mundo capitalista pervierten los alcances dinamizadores de las diversas formas de proximidad humana por medio de articulaciones que limitan la dignidad a una forma de sobrevivencia asociada con la tenencia de capital y a la generación de ganancia.

La desaparición del valor sujeto asociado a lo colectivo, y su restricción a individuo, inhiben, en este momento, la posibilidad de que se produzca una sinergia de visibilizaciónes emergentes, que actué dentro del mismo sistema mundo capitalista actual, como generadora de un mundo otro, pues los sujetos, los colectivos y sus saberes, aún no aparecen como actores consolidados.
De esta manera, lo transdisciplinario es metodológicamente tan complejo que no puede ser aplicado, y lo transcognitivo no se sustenta en saberes auto-validados, reduciéndose entonces a una ecología de saberes diversos. Habrá que desarrollar una nueva hermenéutica de proximidades si se quiere fundamentar, inter-dialogalmente, la emergencia de una sinergia que sea gestora de la alternatividad... de un "otro mundo mejor posible" a través de la co-gestión de nuevos significados y marcos coherentes de valoración e interpretación de la existencia y de las diversas objetividades, institucionales o no, que la rodean.

Lo humano diverso ha de estar en el centro de lo alternativo para lograr la confluencia de múltiples voluntades en un proyecto único de imaginación de la época que de luz a un espíritu desgarrado, que no encuentra la pasión suficiente para recrear la solidez de un mundo en crisis.

La realidad histórica actual se disuelve en su abandono, las relaciones constitutivas de su solidez y significado se han tornado ficticias y frágiles, el mundo deja de ser habitable; los efectos estructurales nocivos del capitalismo no pueden ser disueltos a no ser que sean cortados por su centro.

Necesitamos de las pestes para pensar en curas; la decadencia 
integral de sistema mundo capitalista, no da lugar más que a afirmar la necesidad de nuestro derecho a la vida, por medio la formulación de proyectos de dignificación que constituyan la imaginación de la época: la exploración, por medio de lo posible, de formas de dignificación que re-coloquen la pasión de vida en el centro de la existencia monótona y reiterativa actual. La más sublime inspiración de la conciencia, surge la más terrible condición del ser humano.

\section{El reposicionamiento del ser humano en el mundo}

La crisis integral del sistema mundo capitalista nos ha llevado al colapso de las relaciones de significado dentro de las diversas interacciones que constituyen nuestra cotidianidad. Esto ha implicado un divorcio entre existencia y la vida operado a través de desarticulaciones de significaciones e identidades dentro de los limites conductuales específicos de la sociabilidad capitalista. Por ello, hacia finales de 2009, el aumento del índice de suicidios en Estados Unidos se precipito en un $7.0 \%$, asumiendo una forma particularmente novedosa e inclusiva que hoy día se mantiene, el suicida primero acaba con otro, antes que consigo, como parte de su desastre y frustración. El otro ha perdido significado como sujeto, las relaciones cotidianas de proximidad se enrarecen y finalmente se hacen incomprensibles, el otro ha dejado de ser humano, reduciéndose a objeto anónimo, las relaciones con él solo pueden ser confusas convulsiones de desprecio y horror, amor e interés.

Ante esto, el problema es fundamentar la esperanza en una emergencia de resignificacion, que como un modo de pensar-actuar otro, a través de la sinergia de nuevos sujetos y saberes, resuelva los nudos estructurales de exclusión del sistema mundo capitalista enconado, en este momento, por el colapso del proyecto-mundo neoliberal. Esto exige estructurar una nueva hermenéutica de la posición del ser humano en relación al mundo, que consolide la resignificación ontológica y epistemológica de la realidad, a través de la confirmación antropológica de su condición de constructor de mundos, significador de realidades.

Estamos por ahora lejos de una utopía posibilitadora, de hecho no creo que pueda hablarse de utopía en la medida en que los sujetos posibilitadores de algún nuevo proyecto de resignificacion integral no están consolidados como alternativos, siendo, por ahora, tan solo emergentes, o sea recientemente visibilizados.

Así, es tan solo de esperar que se exploren posibilidades de 
dignificación con la esperanza de que se materialicen como alternativas en la medida en que nuevos sujetos confirmen, en actos particulares, la autoridad del ser humano de redefinir su realidad histórica, de constituirse en actor insilenciables.

En Costa Rica, por fortuna, se está avanzando rápido en esa dirección, ya que no hay más sublime acto de imaginación de la época que el afirmar que un mundo mejor es posible. No hay otra manera de devolver la esperanza a un alma conmovida por las distorsiones vivenciales que ha generado el sistema mundo capitalista, que ratificando el derecho y la posibilidad de superar el fatalismo escatológico del momento y su efectos pervertidores.

$\mathrm{Y}$ si bien se podrían identificar condiciones e incidencias concretas, le es propio al filósofo más que preguntarse por el cómo, cuándo, o el quién, por su fundamento, es decir, proponer una ontología autorizadora y diferente, que evidencie las posibilidades y alcances de lo que un quién realiza cuándo define cómo.

La razón es simple: el mundo no es más que la construcción articulada de segmentaciones ontológicas y totalitarismos epistemológicos, un sistema de relaciones artificiales e intencionales donde la posición de las cosas y el sentido que estas tienen surge del artificio humano, manifestando una racionalidad tan compleja y diversa que su comprensión sólo sería posible de manera transcognitiva y transdisciplinaria.

Todos los animales impactan la realidad que habitan con mayor o menor invasividad, sólo el ser humano la segmenta radicalmente y la reconfigura en relaciones confirmables; sólo el ser humano invade la realidad que habita con un régimen de significación y afirmación tan integral como totalitario. Dentro de ese, sólo es parte del mundo aquello que tiene un significado asignado, una delimitación de sentido que corresponde a un régimen de interpretación, cuyo efecto conductual es crear la coherencia y compresibilidad, necesaria siempre, para sobrellevar la vivencia cotidiana de múltiples experiencias... la realidad del mundo es su realidad histórica.

Toda forma de realidad histórica ha tenido superestructuralmente un régimen de interpretación y valoración que asigna el estatus de real a aquellas entidades que son abarcadas dentro de sus fronteras de sentido, por ello, solamente aquello que es significativo para el ser humano existe. Los significados de los segmentos de realidad que constituyen las cosas del mundo, se configuran desde lugares específicos de enunciación de sentido: clase, privilegios de poder, sexo, raza, 
cientificidad de un saber, por ello es que su "verdad" no es otra cosa que la superposición de conceptos a cosas y experiencias, una relación entre segmentos y significados que se evidencia en la práctica y se confirma tan sólo por medio de la fuerza los argumentos que se utilizan, con vehemencia, para defender su "certeza".

Como creación humana, las relaciones constitutivas del mundo sólo son sólidas en la medida en que se genere un compromiso con su permanencia, pues de lo contrario se deterioran por abandono, como nuestra casa, cuando no reparamos los defectos causados por el paso de los años.

Las artificialidades que constituyen el mundo, surgen de la inteligencia y los diversos intereses humanos, son por ello constructos visibilizados en diversidad de cosas significadas. El ser humano es el centro de sentido del mundo y desde esa posición fundamenta una resignificacion de la realidad histórica como un nuevo proyecto de mundo, que hoy se puede imaginar, desde sujetos y saberes emergentes e insilenciables, aun y cuando no pueda afirmarse como alternativa en sentido estricto. El viejo maestro Olarte atinaba al escribir:

"La realidad, toda la realidad habrá de ser comprendida dentro del movimiento creador de los relativos.
Entre todos los relativos descuella un relativo eminente: el hombre, fuente dinámica para conferir sentido, no absoluto, a todos los demás relativos" (Olarte, 1974:47)

\section{El retorno de lo posible}

La decadencia del mundo convulsiona al espíritu humano hasta destruir la solidez de sus verdades; la esperanza se deshace en muerte provocando una agonía interminable, una forma particular de realidad histórica se ha precipitado hacia su colapso.

La conciencia envenenada con fatalismos, cae de rodillas ante la ontología de un mundo creado ex illo tempore, frente al cual no puede hacer nada. Tanto como el ser humano no puede sobrevivir a su existencia sin esperanza, tampoco puede sobrevivir en el mundo sin certezas. El colapso de los sentidos de ser ha dejado al ser humano deambulando, en el anonimato, por un mundo que le carece de importancia.

La solución posible a este colapso superestructural es la reasignación de significados a la existencia, la configuración de nuevos sentidos de ser en el mundo; pero esto implica un riesgoso abandono de la concepción ontológica tradicional cristiana, que inhibe, epistemológicamente, la transformación del mundo, al colocarlo, 
como resultado de la acción creadora de una entidad metafísica, más allá de la capacidad humana de cambiar el estado de las cosas, pues ese status no depende de la voluntad del ser humano. Abandono peligroso, porque la religión es la única superestructura del sistema mundo capitalista que conserva aún su solidez plena, coherencia y significado; el riesgo es pues que lo que gane el hombre al separarse de la inhibiciones que le siembra su fe, pues puede ser menos que lo que pierda al alejarse de ella.

No por ello nos hemos de separar de una verdad histórica: el mundo no es creación divina, sino una artificialidad humana constituida por relaciones articuladas de segmentos ontológicos y totalitarismos epistemológicos. Su solidez no depende tanto de condiciones materiales, sino de las pasiones que despierta, es por ello que su desprecio, o bien su simple descuido, lo precipita a su desaparición.

Solo el hombre que sueña, que imagina, tiene la pasión suficiente para pensar en alternativas de dignificación a su presente de incertidumbres, solo el alma bella abraza la esperanza con la imaginación de su época; por medio de la imaginación reorganiza su mundo, por medio de la pasión lo transforma.

Como práctica inusual en su rutinaria cotidianidad, la imaginación apasionada explora diversas formas de dignificación de la existencia justo cuando la satisfacción con la vida es negada por la realidad histórica en la que se existe. No en balde las más hermosas utopías que han surgido de la imaginación de la época son confirmación de la vida a través de la reorganización del mundo.

Lejos, sin embargo, estamos de poder hablar de ella como una propuesta materializable. El sujeto histórico que la constituye en mundo alternativo no tiene, en este momento, una expresión única, sino fragmentada. Visible como diversidad de voluntades, el sujeto reconfigurador de significados se encuentra disperso en distintos lugares de la geografía del poder y la existencia cotidiana. La posibilidad de una nueva época histórica en la que un proyecto postcapitalista de mundo se constituya como alternativa de dignificación, para iniciar un humanismo absoluto de historia, sólo puede enunciarse desde la multiplicidad de sujetos y de saberes alternativos.

De esta forma, la reasignación de significados, la cogestión de nuevos sentidos de ser para enfrentar, con dignidad, la vivencia cotidiana de múltiples experiencias, ha de ser pensada desde una hermenéutica de confluencia sinérgica de reivindicaciones opuestas a situaciones de exclusión física y simbólica. La reivindicación de la dignidad 
humana es posible como fragmentación del mundo en diversas regiones de significado y sentido, comprensibles para sujetos que cogestionan formas dignificadas de convivencia social.

Sin duda es de lamentar que esta comprensibilidad sólo sea posible dentro de los colectivos identitarios, fuera de los cuales, el otro es percibido tan solo como objeto de burla, o en el peor de los casos de disimulo, pues el disimulo es un desprecio que se prefiere ocultar.

En todo caso, lo que se ha de destacar es que la praxis de resignificacion se asocia a prácticas alternativas de resistencia y reivindicación. Los nuevos sentidos de ser que emergen permiten a sujetos específicos reencontrarse con significados comprensibles y alternativos a un mundo en decadencia, son significados configuradores de una vivencia cotidiana satisfactoria, festiva y complaciente sin mayor interés que compartir la dulce sensación de la compañía casual de aquellos que nos agradan y luego amamos.

\section{Nuevos sujetos y nuevos significados}

En un mundo que ha perdido su solides, el hombre pierde sus esperanzas y las relaciones humanas se pervierten; si se quiere conocer la verdad del otro, es necesario pensar con malicia sus actos e intenciones. La edénica convivencia de goce y despreocupada inocencia se disipa entre el turbio aire de actitudes enfermizas.

Las relaciones intimas y filies se trastocan en condicionamientos que los encadenan a imposturas, la persona se transforma en otro de un tipo diferente, aceptable solo en su sometimiento a los caprichos del yo, el amor y la amistad ya no constituyen un nosotros, sino una sujeción apropiadora que nos reduce a objetos sin voluntad, inteligencia o deseos propios.

Escondiéndose de la mísera incertidumbre cotidiana, algunos se refugian en actos de intenso tanatos, otros, en pasiones convulsionadas por turbias incertidumbres de amor, aprecio, odio y desprecio simultaneas; algunos, no pocos por cierto, prefieren el uterino del divorcio de todos a través de imposturas fugaces indiferencia $\mathrm{y}$ disimulo; ya no nos es posible convivir con una desinteresada complacencia festiva.

La decadencia del mundo ha hecho que el ser humano pierda la capacidad de aceptar la diversidad y sus diferencias, el divorcio entre el yo y el otro no supera la constitución de nosotros. Lejos estamos de un mundo de tolerancia, el yo sólo puede enfrentar la interacción con los diversos otros si los redu- 
ce a representaciones aparenciales y disimulos.

La relación íntima se estructura entonces dentro de interacciones pervertidas que los convierten en seres desvirtuados, frágiles representaciones de hombres disminuidos a individuos, imagen borrosa de un otro desde lo que, en su complejidad, nos resulta aceptable, por encima de aquello que en él nos es por sí misma abominable. No podemos aceptar al otro con sus defectos sino los hacemos invisibles; pero el otro no es poseedor de defectos, sino de complejidades. Su condición de ser humano no lo hace, para nosotros, sujeto, sino más bien objeto de nuestras perversiones y prejuicios, ya que no podemos simplemente eludirlo, como lo hacemos con aquellas cosas que al no poder imponernos su presencia, les pasamos de largo sin asignarles ninguna importancia.

No hay derechos que nos hagan sujetos, pues no se es sujeto en tanto que se recibe la acción, sino en tanto que se la produce. El ser humano solo es sujeto en tanto se constituye en actor.

Antes de su muerte uno de mis más queridos maestros escribió en su obra:

"Lo real sobrepasa toda especificación parcial del sujeto y el sujeto sobrepasa toda las posibles especificaciones de que es capaz real. El acto primero, constitutivo del sujeto como tal, jamás es más que toda la actualidad de sí mismo, cualquiera que sea la potencialidad de lo real. El acto primero lo sobrepasa mediante el ser, y con él, constituye la antitesis primitiva de toda la ontología." (Soto Badilla, 1986:79-80)

Como sujeto el ser humano concentra en torno a sí a un mundo constituido por aquello que tiene significado y que es para él valioso, ya sean estos objetos, personas, o ideales.

En este mundo el divorcio entre el yo y el otro se resuelve en la constitución del nosotros. En la cotidianidad la compañía desinteresada se celebra a través de múltiples experiencias, el convivir del nosotros es despreocupado.

Sólo se puede convivir de esta manera si los significados dentro de los cuales hacen comprensibles las conductas cotidianas, tanto las inesperadas como usuales, corresponden a regímenes identitarios establecidos. La convivencia festiva, la despreocupada complacencia que nos genera la presencia de aquellos enriquecen con su sutil brillo la penumbra de nuestro decadente mundo, sólo es posible entre sujetos que se aceptan mutuamente en su complejidad y riqueza de diversidades, pasando uno al lado del otro en una rica danza de iniciativas y actividades que enriquecen el 
espacio con movimiento y el tiempo con buena compañía.

Convivir con agrado entre personas sólo es posible si aquello con lo que llenan nuestra diversidad de situaciones y momentos, nos resulta claramente comprensible y aceptable, no por ser lo acostumbrado, sino por ser parte de lo que le es propio a quien es parte de nosotros en nuestro mundo, aún y cuando lo que haga no sea un aspecto de lo que nosotros podemos hacer por nosotros mismos.

Tolerar no es disimular lo que nos repugna, sino trivializar lo que nos sorprende de los que estimamos. Quién mejor que Fromm habrá expuesto lo anterior con mejores palabras que las siguientes:

"Todos somos uno. Las diferencias en talento, conocimiento, son despreciables en comparación con identidad de decencia humana común a todos los hombres. Para experimentar dicha identidad es necesario penetrar desde la periferia hasta el núcleo. Si percibo en otra persona nada más que lo superficial, persigo principalmente las diferencias, lo que nos separa. Si penetro hasta el núcleo, persigo nuestra identidad, el hecho de nuestra hermandad." (Fromm, 1974:59)

La convivencia entre sujetos exige compresibilidad expansiva y aleatoria, tanto lo acostumbrado, que lo que es inesperado ha de ser remitido de alguna categoría valoración e interpretación dentro de un régimen coherente y estable de significados, permitiéndonos entender cada manifestación particular de las identidades como alternativa de identificación consciente de espacios, lugares, tiempos, momentos, sujetos y conductas.

La ruptura y debilitamiento del régimen hegemónico de significados y valoraciones provocado por el colapso del modelo neoliberal de acumulación por desposesión, ha hecho que las identidades configuradas a lo largo de siglos, pierdan coherencia, a grado tal que lo inesperado, lejos de poder ser aceptado como particularidad de aquel que no es aún parte de nosotros, es más bien expresión repugnante de la vulgaridad de un otro que nos resulta disimulable solamente en su anonimato y distancia.

La decadencia del mundo ha hundido al ser humano en una descontrolada ansiedad por el control de lo inesperado, esto nos lleva a centralizar tiránicamente lo que otros hacen dentro de lo que esperamos, deseamos u ordenamos.

En la perversión de relaciones íntimas filiales, la convivencia se ha distorsionado hasta el grado en que el sujeto, para ser tratado como persona, debe ser reducido a un objeto constituido por aquello que complace a aquel que lo acepta como parte de su cotidianidad, 
como si la convivencia con él no fuese un simple evento, sino más bien un privilegio.

Ser realmente lo que somos, sin guardar las conocidas normas de prudencia y apariencia con las que, como nos dictan las buenas costumbres, hemos de comportarnos cuando recién conocemos a otro, es un costoso privilegio, cuyo precio es la burla, el desprecio y la soledad.

Los significados de ser establecidos superestructuralmente como regímenes diversos de comprensión y valoración de conductas, son el resultado de una articulación intencional y de larga data dentro de la sociedad capitalista, en la que diversidad de discursos filosóficos, éticos, políticos, religiosos. Enunciados desde lugares específicos de poder, marcan privilegios y los consolidan, haciendo comprensibles conductas dentro de la cotidianidad de modo tal que se les concedieran usuales, es decir, esperables.

La reducción del ser humano a objeto, en este momento particular de colapso del mundo, no es sino la salida esperable para una conciencia que transita una ruta específica de existencia colonizada por categorías de la individualización capitalista; estructuralmente el régimen de valoración ha sometido a la persona, a lo largo de su propias vivencias, a formas de reducción y exclusión simbólicas tan rutinarias, que en la exacerbación actual de sus alcances, resultan simplemente imperceptibles, o, en el peor de los casos, prescindibles.

Lo extraordinario de este momento es que asociado al colapso del régimen de interpretación y valoración, la insatisfacción cotidiana promueve que tanto los reducidos a lo unidimensional como los invisibilizados resistan las exclusiones y reducciones simbólicas, permitiendo que emerjan nuevos significados. Nos hemos precipitado hacia un cambio integral sobre el cual no tenemos ninguna certidumbre, pero en el cual ciframos nuestras esperanzas, porque los gritos de los que están en el infierno no pueden dirigirse más que hacia el cielo.

No se gestan alternativas sin resistencia a la exclusión, la invisibilizacion y el silenciamiento normativo. El espíritu rebelde explora y se aproxima a lo alternativo constituyéndolo; en su propia vivencia, que no es sino convivencia festiva, propicia el nucleamiento de personas en espacios subterráneos que generan la satisfacción del reconocimiento mutuo.

Tanto la persona como el nosotros reaparecen en una nueva dimensión colectiva; la convivencia comunitaria se resignifica resignificando su cotidianidad. Las comunidades son ahora colectivos y estos, más que espacios y momentos de encuentro casual grato, 
constituyen lugares de aceptación de las diferencias y satisfacción vivencial, de aquí que en ellos, la resistencia adquiera la forma de pasión orgullosa, pues aquí el esfuerzo de uno constituye un esfuerzo de todos. "El trabajo del individuo para satisfacer sus necesidades es tanto la satisfacción de las necesidades de los otros como de las suyas tropiezos, y sólo alcanza la satisfacción de sus propias necesidades por el trabajo de nosotros." (Hegel, 1987:221)

El sujeto desemboca así en productor de nuevas prácticas $\mathrm{y}$ expectativas colectivas y contra normativas, sin embargo, la alternatividad que constituye da lugar a un rango normatividades excluyentes entre los diversos colectivos. La grosera experiencia de ser víctima de exclusión y reducción simbólica no ha logrado que el ser humano concluya que sólo en la unidad de lo diverso habita lo humano. Solo en la sinergia que logre producir la confluencia de múltiples voluntades, la exclusión y denigración simbólica del ser humano desaparece, y no simplemente se soporta o se disimula. La reconfiguración identitaria que se cogestiona dentro de los distintos colectivos como modos de ser y pensar particulares, no pretende una nueva forma de sociabilidad tolerante, sólo evadir la invisibilizacion y la negación simbólica subsistente. No se aspira a desplazar los significados existentes con nuevas formas de ser, pensar y actuar que resulten prerrogativa de todo ser humano, sino solamente lograr el encuentro de los diferenciados en recónditos antros de simulación. Es terrible la dialéctica aparencial de quien, creyéndose libre, esta esclavizado por los mismos prejuicios que lo silenciaban.

La resignificación no crea nuevas realidades, sino valoraciones, redefine los impactos, las cotidianidades, en síntesis, las posibilidades valorativas del mundo. La multiplicidad de experiencias que constituyen nuestra cotidianidad, se enriquece con el encuentro y reconocimiento de lo diverso, su contenido más humano y por ello más bello.

\section{Conclusión}

Desde lo que puede entreverse en el momento actual de dispersión de esfuerzos e iniciativas, un mundo resignificado es diversificado, pues el espacio y tiempo se colonizan con las valoraciones e interpretaciones y relaciones de quienes lo habitan. Las relaciones sociales se fragmentan como una nueva forma de unidad, obligándonos a pasar entre ellos transcognitivamente, o bien, simplemente, intentar disimularlas entre el alcohol, la soledad y la pornografía. 


\section{Bibliografía}

Casirer, Ernst (1982). Antropología filosófi$c a$. México. Fondo de cultura.

Fernández Vásquez, Rodrigo (1979). La razón orgánica. Heredia, Costa Rica. EUNA.

Fromm, Erick (1974). El arte de amar. Argentina. Paidós.

Hegel, G.W.F. (1987). La fenomenología del espíritu. México. Fondo de cultura.

Olarte, Teodoro (1974). El ser y el hombre. San Pedro, Costa Rica. Editorial Fernández Arce.
Reguera, Isidoro (1994). El feliz absurdo de la ética. España. Tecnos.

Saxe, Eduardo (2004). Un mundo que se hunde: los colapsos ecosociales, ontológicos y globales. Brasil. Hileia.

Soto Badilla, José (1986). Hacia un concepto de persona. San Pedro, Costa Rica. EUCR.

Trías, Eugenio (1987). Los límites del mundo. España. Ariel. 
